\title{
WEBSITE USABILITY AND USER \\ EXPERIENCE DURING SHOPPING ONLINE FROM ABROAD
}

\author{
Jozef Bucko, Lukáš Kakalejčík
}

\section{Introduction}

Website usability and user experience are key measures of website quality (Sivaji \& Tzuaan, 2012) and a key component of the websites that are commercially successful (Lowry et al., 2006). For today's users, there are so many options in the environment of the Internet that each misstep in meeting user's expectations might result in loss of the potential customer (Kakalejčík, 2016). Krug (2014) consider the usable website to be a place where a person of average (or even below average) ability and experience can figure out how to use the website in order to accomplish something without it being more difficult than is the value obtained by using it. The usable website has several attributes. It is useful, learnable, memorable, effective, efficient, desirable and delightful. Moreover, Aziz, Kamaludin, and Sulaiman (2013) add satisfaction and accessibility as additional features. Casaló, Flavián, and Guinalíu (2008) claim that perceived usability is an indirect factor that affects customer loyalty and positive word-of-mouth through satisfaction. In this case, usability helps to satisfy the needs of the customer and as a result, a greater level of loyalty and positive word-of-mouth will be created. Furthermore, Braddy, Meade, and Kroustalis (2008) found that positive company's website user experience can affect organizational attractiveness as a potential employer.

In order to ensure the website is userfriendly, user experience testing should be conducted. User experience testing is a method of obtaining direct user feedback on a website or other product by observing and interviewing user while they perform some tasks while using the website or product (Sivaji \& Tzuaan, 2012). However, in this case, the best practice would be building a website based on used conventions of user experience and then confirm its usability by user experience testing. This is partially connected to agile development during which product owner confirms that the website meets established functionality (Sutherland, 2014). In this way, the company is prevented from additional development cost (Ries, 2011).

Cappel and Huang (2015) provide us with The Iceberg Model of Website Usability. This model is devided into three regions:

1. The "tip" of the Iceberg: websites in this category are characterized by one or more serious design issues or problems that attract a lot of attention - shocking colours, oversized graphics etc. Users usually react by quick abandonment. These websites typically require moderate to radical redesign.

2. "Middle Mishaps": this region focuses on the presence of errors, instead of following Web design practices. Some specific problems include grammar, spelling or punctuation errors, non-functioning links, poorly performing search function etc. These errors are less serious. Depending on the quantity and severity of the issues, these websites require remedial actions that are part of moderate redesign.

3. Untapped Opportunities": this type of errors represents the inability to provide certain Web design elements that users have come to expect or it does not take full advantage of the World Wide Web. Websites might miss site map, search, and navigation or users context to their current location within the website. These missing elements are not of dramatic nature and many users will not notice them. However, the overall impact is based on quantity and severity of missing elements (Cappel \& Huang, 2015).

Pallot and Pawar (2012) provide us with Holistic model of user experience, which is briefly presented in Tab. 1. 


\section{Tab. 1: Holistic model of user experience}

\begin{tabular}{l|l|l} 
Experience type & \multicolumn{1}{|c}{ Definition } & \multicolumn{1}{|c}{ Elements } \\
\hline Perceptual & $\begin{array}{l}\text { Reflect the experience of taking information } \\
\text { via the senses }\end{array}$ & $\begin{array}{l}\text { Sensory (Sensitivity) } \\
\text { Perceptive Appreciation }\end{array}$ \\
\hline Cognitive & $\begin{array}{l}\text { Reflect the cognitive experience in processing } \\
\text { information and applying knowledge }\end{array}$ & Cognitive Economics \\
\hline Reciprocal & $\begin{array}{l}\text { Reflect the experience of distributed and } \\
\text { situated cognition }\end{array}$ & $\begin{array}{l}\text { Distributed Cognition } \\
\text { Situated Cognition }\end{array}$ \\
\hline Social & Reflect the individual experience in a group & $\begin{array}{l}\text { Interpersonal Relationships } \\
\text { Social Interaction } \\
\text { Group dynamics } \\
\text { Group Enhancement } \\
\text { Group Confidence }\end{array}$ \\
\hline Emotional & $\begin{array}{l}\text { Reflect the complex psycho physiological } \\
\text { experience of an individual's state of mind }\end{array}$ & $\begin{array}{l}\text { Physiological State } \\
\text { Emotional Connection }\end{array}$ \\
\hline Cultural & $\begin{array}{l}\text { Reflect individual experience within } \\
\text { a community }\end{array}$ & Habits and conventions \\
\hline Empathical & $\begin{array}{l}\text { Reflect individual experience of being helpful } \\
\text { with others }\end{array}$ & Caring \\
\hline Technological & $\begin{array}{l}\text { Reflect individual experience of using } \\
\text { technological artefacts }\end{array}$ & $\begin{array}{l}\text { Innovativeness } \\
\text { Performance } \\
\text { Friendliness }\end{array}$ \\
\hline Economical & $\begin{array}{l}\text { Reflect individual experience of the created } \\
\text { value (business model) }\end{array}$ & $\begin{array}{l}\text { Satisfaction } \\
\text { Inclusion }\end{array}$ \\
\hline Legal and Ethical & $\begin{array}{l}\text { Reflect individual experience of user } \\
\text { protection }\end{array}$ & $\begin{array}{l}\text { Ownership } \\
\text { Privacy } \\
\text { Security }\end{array}$ \\
\hline
\end{tabular}

Source: own processing based on Pallot and Pawar (2012)

When comparing the Holistic model of user experience with The Iceberg Model of Website Usability by Cappel and Huang (2015), we can see that Holistic model takes more variables into the account. Model of Cappel and Huang is more focused on technical aspects of user experience and customary conventions. However, Holistic model tries to dive deeper and find other variables that are more related to user's inner feelings. We agree that user experience is based on more than usability of the website but we consider further variables to be intricately measurable. In fact, for users, it is difficult to describe their inner feelings and by observation of users, it is not possible to extract them, too. Furthermore, as Law and van Schaik (2014) discuss, in UX empirical studies, variables such as flow, aestheticbeauty, emotion, enjoyment, affect, arousal/ valence, hedonic quality, intrinsic motivation, presence, engagement, attractiveness, and satisfaction are observed. Dingli and Cassar (2014) proposed Intelligent Usability Evaluation framework which goal is to minimize the amount of human intervention necessary to evaluate the usability of the website. By entering a homepage URL, the user issues a request to have a list of interior webpages to be evaluated for usability. The results of the experiments concluded that this tool adequately models human judgment when detecting usability violations. However, based on our real-world experience, we conclude that the human behavior is so unpredictable that the use of this framework is limited and its accuracy may vary from case to case. Montero, González, Lozano, and Vanderdonckt (2005) introduced a framework where experience and web site development are linked using qualitative good practices. Sohrabi, Mahmoudian, and Raeesi 
(2011) proposed framework for improving e-commerce websites usability using a hybrid genetic algorithm and neural network system. They showed that the proposed framework changes the website structure based on the two criteria, i.e., sales conversion rate and average pre-purchase page views and finally leading to improved website usability.

This paper focuses on the determination of key website issues when purchasing goods from online stores from abroad, and dividing Internet users into categories - clusters with similar features. In order to accomplish abovementioned, we are conducting factor analysis in order to create new latent variables by eliminating the number of variables in the original data matrix. Afterwards, we conduct cluster analysis using fuzzy algorithm FANNY, in order to determine the degree of membership under which users in countries belong to the particular clusters.

\section{The Current State of Discussed Issue}

The main objective of the study conducted by Zaied et al. (2015) was to propose usability testing technique to evaluate e-learning and e-training usability. In order to define user's perspectives about the existence of usability criteria that affect the success of the website, authors distributed a questionnaire to 80 students and 16 web developers. The study revealed that for students, personalization is the most important criterion of usability of observed websites. Accessibility, navigation and ease of use were in the first half of important criteria. The content was the least important factor, as the study said. This is a paradox when e-learning and e-training websites are observed. However, for website developers, the content is the most important criterion, followed by navigation and ease of use. They also consider personalization as the least important. By comparing the results of this study, we can see that different groups of users might have different needs and expectations towards website usability.

Data analysis in the study of Pilar and García (2014) demonstrated that websites with a high level of usability significantly eases browsing and reduce the browsing time of users. Moreover, they reduce the number of errors user commits during the purchasing process, too. Due to good usability, the user also perceives risk at a lower rate. The results of a study by Liu, Li, and $\mathrm{Hu}$ (2013) showed that the perceived website ease of use, visual appeal and product availability are important online impulses towards online purchases. Instant gratification and normative evaluation were found to mediate the effects of website cues on the urge to buy impulsively.

In previous research (Bucko, Ferencová, \& Kakalejčík, 2015) was conducted in February and March of 2015. The research sample consisted of 221 participants from Slovak universities. The results of questionnaire survey showed that selected factors of user experience are more important for users than others. Detailed pictures, description, and easy navigation were more important than the graphic design of the website, perceived security or mobile optimization. We were also focused on delivery time and payment methods (which will be subject of research in this study) that seemed to be more important. However, in this study, it was proved that the price is the most significant factor that can influence the online purchase.

Green and Pearson (2011) examined the website usability on e-commerce websites with the use of structural equation model. The sample consisted of 344 participants. The results showed that design satisfaction has a positive influence on intention to make a transaction with the website. Perceived usefulness and perceived ease of use were positive predictors of design satisfaction. Perceived risk is not a predictor of design satisfaction. Trust in the website was found to be a significant and negative predictor of perceived risk. Perceived ease of use had a significant and positive relationship with perceived usefulness. Design credibility was found to be a significant and positive predictor of trust. Content and interactivity were found to be a significant predictor of perceived usefulness. Navigability, responsiveness, and download delay are significant predictors of perceived ease of use. Many of these findings can be considered as expected and in the case of opposite results, we would be able to talk about a paradox.

Results of mentioned studies help us compare our findings that will be presented in the following parts of our paper.

\section{Objectives and Methods}

The main objective of our study was to analyze the website usability issues users 
have when purchasing products from abroad. By decomposition of the main objective, 2 partial objectives were defined. The first partial objective was focused on the determination if there are any correlations among variables so the appropriate factors could be created. The second partial goal was focused on the definition of groups of website users based on the similarities in behavior during the purchasing process. In order to achieve given objectives, the secondary data from Consumer Barometer was used. Data in the Consumer Barometer is gathered from two sources:

1. core questionnaire that is focused on the population of adults;

2. connected customer study that is used to enumerate the total audit population and is used to weight the results (Consumer Barometer, 2015).

The sample consists of the nationally representative population (online and offline) with the age of $16+$ in each country surveyed except China, India, South Korea, Malaysia, Philippines, Vietnam, and Japan (age of 20+). Sample consisted of 85,180 participants from 56 countries $[\mathrm{n}$ (Europe) $=29, \mathrm{n}($ Asia $)=17$, $\mathrm{n}$ (America) $=5, \mathrm{n}$ (Africa) $=3$, Australia and $\mathrm{New}$ Zealand] (Consumer Barometer, 2015).

Surveys were administered by TNS Infratest on behalf of Google. Survey data was collected in all countries via telephone or face-to-face interviewing. Surveys were administered from January to March 2014 and from January to March 2015. For the purpose of this study, we used the answers on question "Which of these website issues - if any - have ever prevented you from purchasing a product online from abroad?"

As there is a presumption of correlations among data, we decided to find out if we could eliminate the number of variables and create new latent variables that would carry as much information as possible in the smaller amount of variables. Based on this, principal components analysis was conducted. The main objective of the factor analysis is to evaluate the structure of relationships among observed variables in order to find correlations among variables. By using factor analysis, we are able to reduce the number of variables and create new (latent) variables - factors (Stankovičová \& Vojtková, 2007). Principal components analysis was used as a method to estimate the parameters of factor model. Principal components analysis is a statistical method which uses orthogonal transformation to convert the set of observations of correlated variables into set of variables which are not correlated. If $k$ is number of principal components and $n$ represents the number of variables, $k \leq m(\mathrm{Wu}$, 2016). As principal components analysis (and factor analysis in general) is commonly used method, the detailed description wouldn't add any contribution to the value of this paper. However, more information about the method could be found in Meloun et al. (2012). As our goal is not to determine nor describe particular factors, the factor score will be used as an input into fuzzy clustering.

Afterwards, in order to find groups of users based on their similarities, we used fuzzy clustering. In general, clustering is a technique that allows creation of subsets from the data called clusters. This partition has its common features, such as homogeneity within clusters (objects belonging to the cluster are as similar as possible), and heterogeneity between clusters (objects belonging to different clusters are as distant as possible) (Höppner et al., 1999). Commonly used clustering methods (hierarchical and non-hierarchical) assign objects to the particular clusters while one object belongs only to one particular cluster. In a real world, the uncertainty in the data might be spotted (Kauffmann \& Rousseeuw, 2005). It especially applies in case of the Internet users, as the uniqueness of these users doesn't allow assigning them to one cluster only. In fuzzy clustering, the object is not assigned to one particular cluster but instead, each object is spread out over the various clusters. The degree of belonging to the cluster/s is quantified by means of membership coefficient that range from 0 to 1 . The main advantage of hard clustering is that it yields more detailed information on the structure of the data. This might be sometimes considered as a disadvantage, too, as amount of outcomes increases with the amount of input data and thus are more difficult to understand (Höppner et al., 1999; Kauffmann \& Rousseeuw, 2005).

Majority of clustering algorithms are based on objective function. The optimal classification is thus determined by minimization of the objective function itself. By using this type of clustering, each cluster is represented by cluster prototype which consists of the cluster center and information about shape of the 
cluster. Degrees of membership are calculated from the distances between data points and cluster centers. The lower distance between the cluster center and data point, the greater degree of membership is in case of this particular cluster (Timm et al., 2004). Abu-Jamous et al. (2015) list several algorithms suitable for fuzzy clustering: fuzzy c-means, FANNY, fuzzy c-shell, Funny cluster indices. Krishnapuram et al. (2001) consider FANNY algorithm to be among the most reliable ones, this is why the same algorithm will be used for analysis in our paper. The objective of FANNY algorithm is to minimize the following objective function:

$$
\sum_{v=1}^{k} \frac{\sum_{i=1}^{n} \sum_{j=1}^{n} u_{i v}^{r} u_{j v}^{r} d(i, j)}{2 \sum_{j=1}^{n} u_{j v}^{r}}
$$

where $n$ represents the number of observations, $k$ represents the number of clusters, $r$ represents the membership exponent and $d(i, j)$ represents the difference between observations $i$ and $j$. If $r \rightarrow \infty$, the complete fuzziness occurs, while membership $u_{i v}=1 / k$. In this situation, each data point will be assigned to all clusters with the same value of degree of membership. Compared to other fuzzy clustering methods, FANNY algorithm provides its user with several advantages. It accepts the difference matrix and in case of spherical clusters, the algorithm is more robust (Maechler et al., 2014). The use of this algorithm allows observing memberships to the groups based on particular segmentation feature (such as country). This partition of users will allow optimizing the user experience to more specific requirements by combining factors included in the particular clusters.

In addition to principal component analysis and fuzzy clustering, we also used Pearson correlation and descriptive statistics (table, bar plot, mean, standard deviation).

\section{Results and Discussion}

In the beginning of our analysis, we conducted principal components factor analysis. By creating a correlation matrix, we found out that the majority of variables correlate. This indicated that the use of factor analysis might be a proper procedure to analyze our data. However, we had to conduct additional tests in order to make sure the method is suitable. For the following computations, we used psych package in R. First, we conducted Kaiser-Meyer-Olkin test in order to determine if the use of factor analysis is appropriate. The overall value of 0.82 confirmed that factor analysis was a suitable method for data analysis. With the use of Bartlett's sphericity test, we were able to reject the null hypothesis that the variables are orthogonal as observed p-value equals 4.479266e-75. After this initial steps, we needed to determine

\section{Tab. 2: Importance of components}

\begin{tabular}{l|c|c|c} 
& Standard deviation & Proportion of Variance & Cumulative Proportion \\
\hline Comp.1 & 2.53 & 0.49 & 0.49 \\
\hline Comp.2 & 1.61 & 0.20 & 0.69 \\
\hline Comp.3 & 1.02 & 0.08 & 0.77 \\
\hline Comp.4 & 0.79 & 0.05 & 0.82 \\
\hline Comp.5 & 0.71 & 0.04 & 0.86 \\
\hline Comp.6 & 0.66 & 0.03 & 0.89 \\
\hline Comp.7 & 0.59 & 0.03 & 0.92 \\
\hline Comp.8 & 0.55 & 0.02 & 0.94 \\
\hline Comp.9 & 0.48 & 0.02 & 0.96 \\
\hline Comp.10 & 0.44 & 0.01 & 0.98 \\
\hline Comp.11 & 0.37 & 0.01 & 0.99 \\
\hline Comp.12 & 0.33 & 0.01 & 0.99 \\
\hline Comp.13 & 0.28 & 0.01 & 1.00 \\
\hline
\end{tabular}


Tab. 3: Principal components analysis, rotation = Varimax

\begin{tabular}{l|c|c|c|c|c|c}
\multicolumn{1}{c|}{ Problem } & PC1 & PC2 & PC3 & h2 & u2 & com \\
\hline The website crashed & 0.87 & 0.15 & 0.06 & 0.79 & 0.21 & 1.10 \\
\hline Loading was too slow & 0.84 & 0.11 & 0.26 & 0.78 & 0.22 & 1.20 \\
\hline The website didn't run on my mobile device & 0.91 & -0.06 & 0.03 & 0.84 & 0.16 & 1.00 \\
\hline Navigation was confusing & 0.78 & 0.24 & 0.16 & 0.70 & 0.30 & 1.30 \\
\hline Process for ordering wasn't clear & 0.23 & 0.69 & 0.50 & 0.78 & 0.22 & 2.10 \\
\hline No proper translation in my local language & 0.38 & 0.07 & 0.86 & 0.89 & 0.11 & 1.40 \\
\hline Poor design & 0.53 & 0.65 & -0.21 & 0.75 & 0.25 & 2.10 \\
\hline Poor or badly written content & 0.35 & 0.80 & -0.03 & 0.76 & 0.24 & 1.40 \\
\hline The website seen insecure & 0.28 & 0.87 & 0.10 & 0.84 & 0.16 & 1.20 \\
\hline No contact or help desk available & 0.78 & 0.29 & 0.19 & 0.73 & 0.27 & 1.40 \\
\hline Delivery times too long & 0.63 & 0.21 & 0.33 & 0.56 & 0.44 & 1.80 \\
\hline No international shipping offered & -0.03 & 0.89 & 0.00 & 0.80 & 0.20 & 1.00 \\
\hline No suitable or convenient payment methods & -0.06 & 0.84 & 0.38 & 0.85 & 0.15 & 1.40 \\
\hline
\end{tabular}

how many components (factors) will be used in the analysis. As presented in Tab. 2, it was recommended to use 3 components which describe $77 \%$ of the cumulative variance.

Afterward, we conducted principal components analysis with 3 components (PC1, PC2, PC3) without any rotation. Standardized loadings didn't show clear results. Instead, we weren't able to conclude which variable belongs to which factor. Based on this, we used Varimax rotation in order to make the results definite. To rotate the factors, we used GPArotation package in R. The summary is displayed in Tab. 3.

Results in Tab. 3 point to the fact that 2 variables (Process for ordering wasn't clear, Poor design) do not befit to one particular component. Based on this fact, we removed those 2 variables from the dataset and repeated the analysis. KaiserMeyer-Olkin test (Overall MSA $=0.82$ ) and

\section{Tab. 4: Importance of components}

\begin{tabular}{l|c|c|c} 
& Standard deviation & Proportion of Variance & Cumulative Proportion \\
\hline Comp.1 & 2.33 & 0.49 & 0.49 \\
\hline Comp.2 & 1.55 & 0.22 & 0.71 \\
\hline Comp.3 & 0.93 & 0.08 & 0.79 \\
\hline Comp.4 & 0.78 & 0.06 & 0.85 \\
\hline Comp.5 & 0.65 & 0.04 & 0.88 \\
\hline Comp.6 & 0.60 & 0.03 & 0.92 \\
\hline Comp.7 & 0.57 & 0.03 & 0.95 \\
\hline Comp.8 & 0.47 & 0.02 & 0.97 \\
\hline Comp.9 & 0.38 & 0.01 & 0.98 \\
\hline Comp.10 & 0.35 & 0.01 & 0.99 \\
\hline Comp.11 & 0.32 & 0.01 & 1.00 \\
\hline
\end{tabular}




\section{Tab. 5: Principal components analysis, rotation $=$ Varimax}

\begin{tabular}{|c|c|c|c|c|c|}
\hline Problem & PC1 & PC2 & h2 & $\mathbf{u} 2$ & com \\
\hline The website crashed & 0.86 & 0.11 & 0.76 & 0.24 & 1.00 \\
\hline Loading was too slow & 0.88 & 0.11 & 0.78 & 0.22 & 1.00 \\
\hline The website didn't run on my mobile device & 0.89 & -0.09 & 0.80 & 0.20 & 1.00 \\
\hline Navigation was confusing & 0.81 & 0.24 & 0.71 & 0.29 & 1.20 \\
\hline No proper translation in my local language & 0.58 & 0.15 & 0.36 & 0.64 & 1.10 \\
\hline Poor or badly written content & 0.35 & 0.76 & 0.70 & 0.30 & 1.40 \\
\hline The website seen insecure & 0.31 & 0.86 & 0.84 & 0.16 & 1.30 \\
\hline No contact or help desk available & 0.81 & 0.26 & 0.72 & 0.28 & 1.20 \\
\hline Delivery times too long & 0.70 & 0.21 & 0.53 & 0.47 & 1.20 \\
\hline No international shipping offered & -0.01 & 0.91 & 0.82 & 0.18 & 1.00 \\
\hline \multirow[t]{2}{*}{ No suitable or convenient payment methods } & 0.05 & 0.89 & 0.80 & 0.20 & 1.00 \\
\hline & PC1 & PC2 & & & \\
\hline SS loadings & 1.00 & 1.00 & & & \\
\hline Proportion Var & 0.42 & 0.29 & & & \\
\hline Cumulative Var & 0.42 & 0.71 & & & \\
\hline Proportion Explained & 0.60 & 0.40 & & & \\
\hline Cumulative Proportion & 0.60 & 1.00 & & & \\
\hline
\end{tabular}

Bartlett's sphericity test (we rejected $\mathrm{HO}$ with $\mathrm{p}$-value $=1.486896 \mathrm{e}-63$ ) proved that the use of factor analysis is appropriate. The analysis of the importance of the components presented in Tab. 4 suggests that for this analysis, 2 components are suitable. Those 2 components describe $71 \%$ of the cumulative variance.

We again run principal components analysis with 2 components (PC1, PC2) without, and afterward, with the use of Varimax rotation. Tab. 5 presents standardized factor loadings after the rotation procedure.

In Tab. 5, we can see that component or factor 1 contains 7 variables and factor 2 contains 4 variables. We can conclude that the rotation was effective as it is possible to see that almost each variable has a high degree of belonging to the particular factor. The exception is represented only by the variable "No proper translation in my local language". However, it is clear that this variable belongs to the principal component 1. As an interpretation of these factors wouldn't be clear we decided to skip this step. As the last action in factor analysis, we created a correlation matrix from the factor score. As displayed in Tab. 6, correlation coefficients are close to 0 , as was expected.

We used factor score in order to perform cluster analysis. As we did not describe factors, there might come a question why we needed to rotate the components and remove the variables that could affect the final solution. Once we used only factor score from non-rotated solution as an input for fuzzy clustering. The proposed

\section{Tab. 6: Correlation matrix of factor score}

\begin{tabular}{l|c|c} 
& PC1 & PC2 \\
\hline PC1 & $1.000000 \mathrm{e}+00$ & $-2.175974 \mathrm{e}-16$ \\
\hline PC2 & $-2.175974 \mathrm{e}-16$ & $1.000000 \mathrm{e}+00$ \\
\hline
\end{tabular}




\section{Fig. 1: K-means optimal number of clusters}

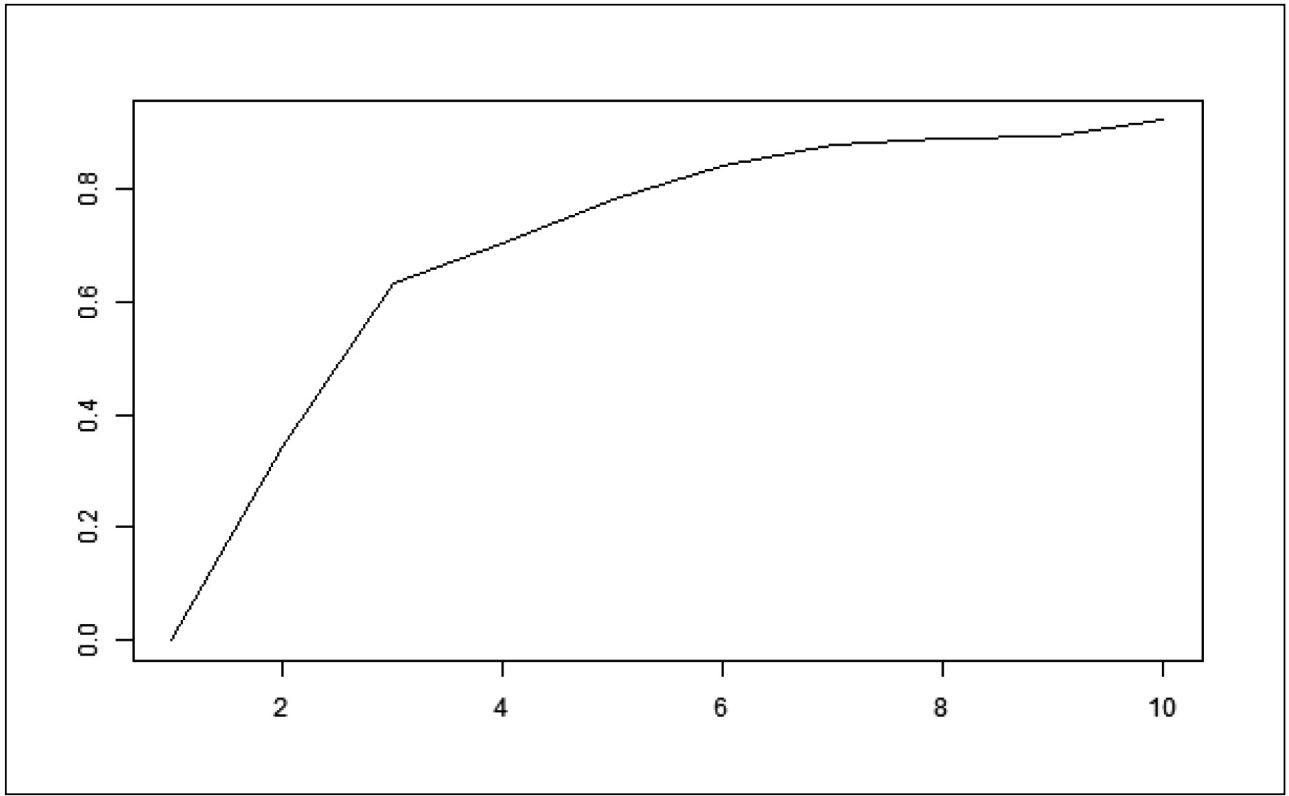

Source: own processing using $\mathrm{R}$

number of cluster was 2 . Once we used it as an input, the results of fuzzy clustering appeared to be a complete fuzzyness, as there were same degrees of membership for each object assigned to clusters. That was the reason why we used rotated solution of factor analysis.

As was defined in Objectives and Methods, the fuzzy logic shows a degree of belonging to cluster for each point rather than belonging solely to one cluster. In the beginning, we needed to determine the optimal number of clusters for analysis. We accomplished that by computing the optimal number of clusters using several other, more frequently used, clustering methods - Ward, Median, and k-means. Ward method suggested that an optimal number of clusters is 3 . The median method suggested an optimal number of clusters of 2 . For determination of clusters with Ward and Median method, we used $\mathrm{R}$ package NbClust. Fig. 1 displays the suggested number of clusters recommended by k-means. As possible to see, the optimal number of clusters is 3 . Based on suggestions of abovementioned clustering methods, we decided to use 3 clusters in our analysis.
To conduct a fuzzy clustering analysis, we used FANNY package in R. During execution of fuzzy clustering analysis, we computed the degree of membership to particular clusters (C1, C2, C3) as long as belonging to particular cluster (M). Results are presented in Tab. 7.

As degrees of membership are presented in Tab. 7, we can claim that when analyzing some of the countries (for example Romania), we cannot confirm that the analyzed country belongs unambiguously to one particular cluster. It is possible to observe that the degrees of memberships are very close and this distance among degrees of membership to the particular cluster should be a subject of further discussion. Fig. 2 presents the distribution of countries to particular clusters in the form of clusplot.

As clusters couldn't be explained based on the factors, we calculated the mean of each variable in order to find differences among clusters. Fig. 3 presents the comparison of clusters based on data presented in Tab. 7 . As we can see in the Fig. 3, there are significant differences in perception of problems connected to Factor 1 by users from countries 


\section{Tab. 7: Degree of cluster membership and clustering of analysed countries}

\begin{tabular}{l|c|c|c|c|l|c|c|c|c}
\multicolumn{1}{c|}{ Country } & C1 & C2 & C3 & M & Country & C1 & C2 & C3 & M \\
\hline Austria & 0.43 & 0.24 & 0.33 & 1 & Ukraine & 0.20 & 0.58 & 0.23 & 2 \\
\hline Belgium & 0.58 & 0.20 & 0.23 & 1 & United Kingdom & 0.30 & 0.47 & 0.23 & 2 \\
\hline Bulgaria & 0.30 & 0.46 & 0.24 & 2 & Kenya & 0.28 & 0.32 & 0.39 & 3 \\
\hline Croatia & 0.30 & 0.48 & 0.21 & 2 & Nigeria & 0.27 & 0.48 & 0.25 & 2 \\
\hline Czech Republic & 0.27 & 0.55 & 0.18 & 2 & South Africa & 0.27 & 0.46 & 0.27 & 2 \\
\hline Denmark & 0.26 & 0.57 & 0.17 & 2 & Israel & 0.44 & 0.19 & 0.37 & 1 \\
\hline Estonia & 0.62 & 0.20 & 0.18 & 1 & Saudi Arabia & 0.24 & 0.41 & 0.35 & 2 \\
\hline Finland & 0.48 & 0.22 & 0.30 & 1 & Turkey & 0.20 & 0.57 & 0.23 & 2 \\
\hline France & 0.42 & 0.21 & 0.36 & 1 & UAE & 0.28 & 0.29 & 0.43 & 3 \\
\hline Germany & 0.64 & 0.17 & 0.19 & 1 & Argentina & 0.22 & 0.61 & 0.17 & 2 \\
\hline Greece & 0.25 & 0.58 & 0.17 & 2 & Brazil & 0.23 & 0.23 & 0.55 & 3 \\
\hline Hungary & 0.31 & 0.50 & 0.19 & 2 & Canada & 0.63 & 0.16 & 0.21 & 1 \\
\hline Ireland & 0.44 & 0.19 & 0.38 & 1 & Mexico & 0.27 & 0.26 & 0.47 & 3 \\
\hline Italy & 0.23 & 0.56 & 0.21 & 2 & USA & 0.27 & 0.50 & 0.23 & 2 \\
\hline Latvia & 0.62 & 0.20 & 0.18 & 1 & Australia & 0.50 & 0.18 & 0.32 & 1 \\
\hline Lithuania & 0.31 & 0.51 & 0.18 & 2 & China & 0.24 & 0.22 & 0.54 & 3 \\
\hline Netherlands & 0.52 & 0.28 & 0.20 & 1 & Honk Kong & 0.33 & 0.19 & 0.49 & 3 \\
\hline Norway & 0.48 & 0.32 & 0.20 & 1 & India & 0.23 & 0.45 & 0.32 & 2 \\
\hline Poland & 0.19 & 0.60 & 0.21 & 2 & Indonesia & 0.22 & 0.50 & 0.28 & 2 \\
\hline Portugal & 0.63 & 0.16 & 0.20 & 1 & Japan & 0.20 & 0.61 & 0.19 & 2 \\
\hline Romania & 0.37 & 0.27 & 0.36 & 1 & Malaysia & 0.29 & 0.20 & 0.51 & 3 \\
\hline Russia & 0.22 & 0.57 & 0.21 & 2 & New Zealand & 0.44 & 0.20 & 0.36 & 1 \\
\hline Serbia & 0.54 & 0.27 & 0.20 & 1 & Philippines & 0.24 & 0.19 & 0.56 & 3 \\
\hline Slovakia & 0.24 & 0.60 & 0.17 & 2 & Singapore & 0.31 & 0.22 & 0.47 & 3 \\
\hline Slovenia & 0.48 & 0.23 & 0.30 & 1 & South Korea & 0.22 & 0.47 & 0.30 & 2 \\
\hline Spain & 0.27 & 0.55 & 0.18 & 2 & Taiwan & 0.30 & 0.18 & 0.52 & 3 \\
\hline Sweden & 0.60 & 0.21 & 0.19 & 1 & Thailand & 0.23 & 0.22 & 0.55 & 3 \\
\hline Switzerland & 0.58 & 0.18 & 0.24 & 1 & Vietnam & 0.26 & 0.23 & 0.51 & 3 \\
\hline & & & & & & & \\
\hline
\end{tabular}

in Cluster 3. These users are more sensitive to website usability compared to countries in Cluster 1 or 2 . Moreover, they demand the availability of customer support and they are not willing to purchase products which delivery takes too long. Nevertheless, there are not significant differences between Cluster 3 and Cluster 1 in problems connected to Factor 2, we can see that users in these countries might have a problem during purchasing process when there are not suitable payment methods available, no international shipping available or when the website seems insecure. The majority of countries in Cluster 3 are from the east of Asia, accompanied by UAE, Mexico, Brazil, and Kenya. However, in this particular cluster, Kenya and UAE represent the outliers. We can conclude that online retailers should be more focused on website usability when addressing the potential customers from these countries, as there is a higher probability that users abandon the website because of poor 


\section{Fig. 2: Clusplot of countries}

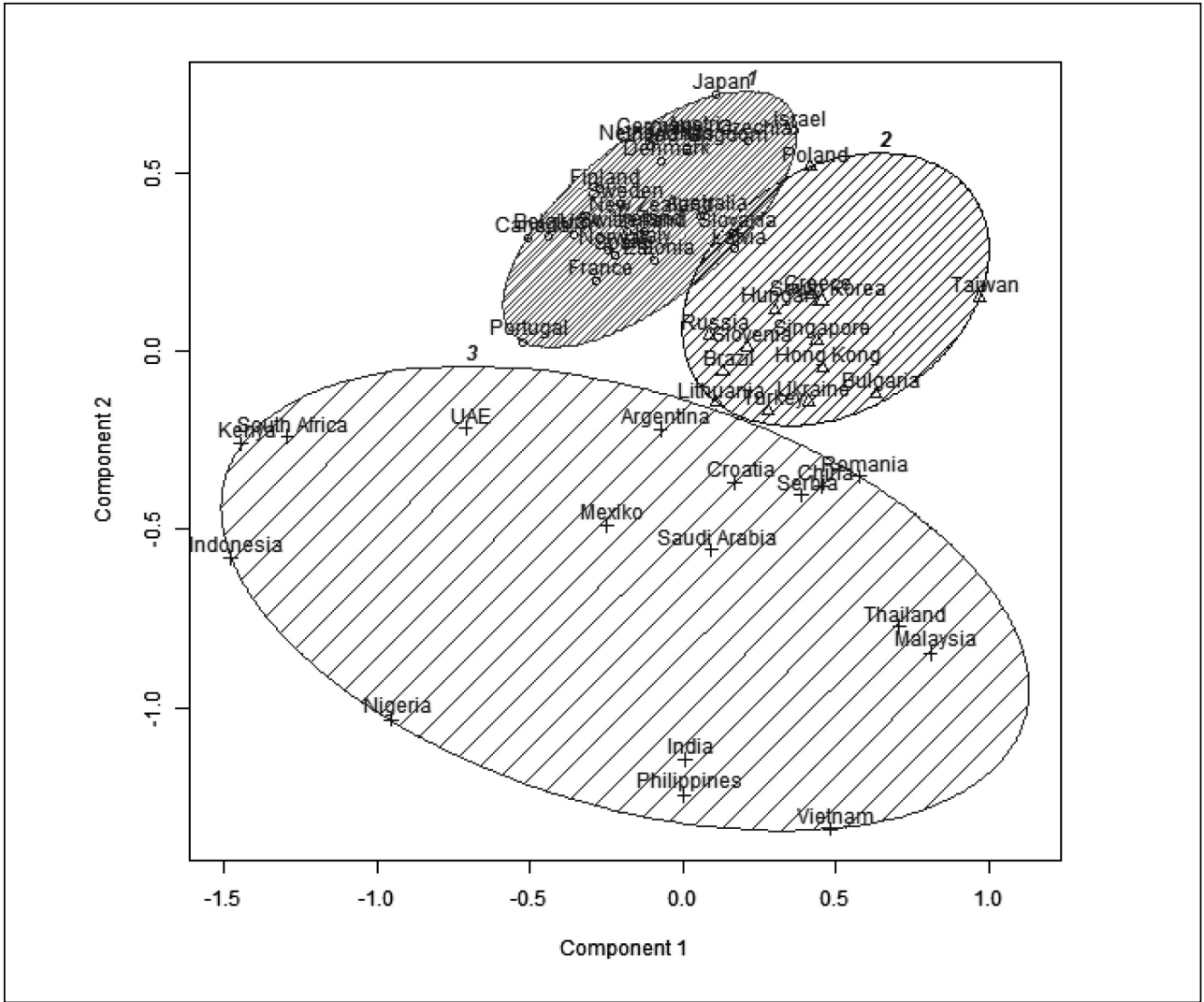

Source: own processing using $\mathrm{R}$

user experience during the online purchasing process.

There is an evidence that perception of usability issues of users from countries associated in Cluster 2 is lower compared to Cluster 1 or 3 . As we can see, the main issue when purchasing products online from abroad is the delivery time. As presented in Tab. 7, this cluster is composed of countries from Asia, Europe, the rest of the African countries, USA. We can conclude that users from this cluster of countries are not affected by user experience when purchasing a product online from abroad. Cluster 1 is very similar to Cluster 2 , however, we can see some of the issues that are crucial for this type of user. We can see that users from Cluster 2 demand the assurance of website security, they are concerned about the impossibility of international shipping and their purchasing process might be disrupted when there is not a convenient payment method. When comparing the rest of the variables, values are very similar to those in Cluster 2 . This cluster is composed of countries of Europe, Israel, Canada, Australia and New Zealand. We can also see that the length of delivery time is a key issue in the online purchasing process for users in each cluster.

However, characteristics of the clusters cannot be generalized across all countries in particular clusters. Notice, that the results of fuzzy clustering presented the degree of membership to the particular cluster. Based on this, we recommend combining the characteristics of the clusters when analyzing countries where degrees of memberships to the clusters are close to each 


\section{Fig. 3: Visual interpretation of conducted fuzzy cluster analysis}

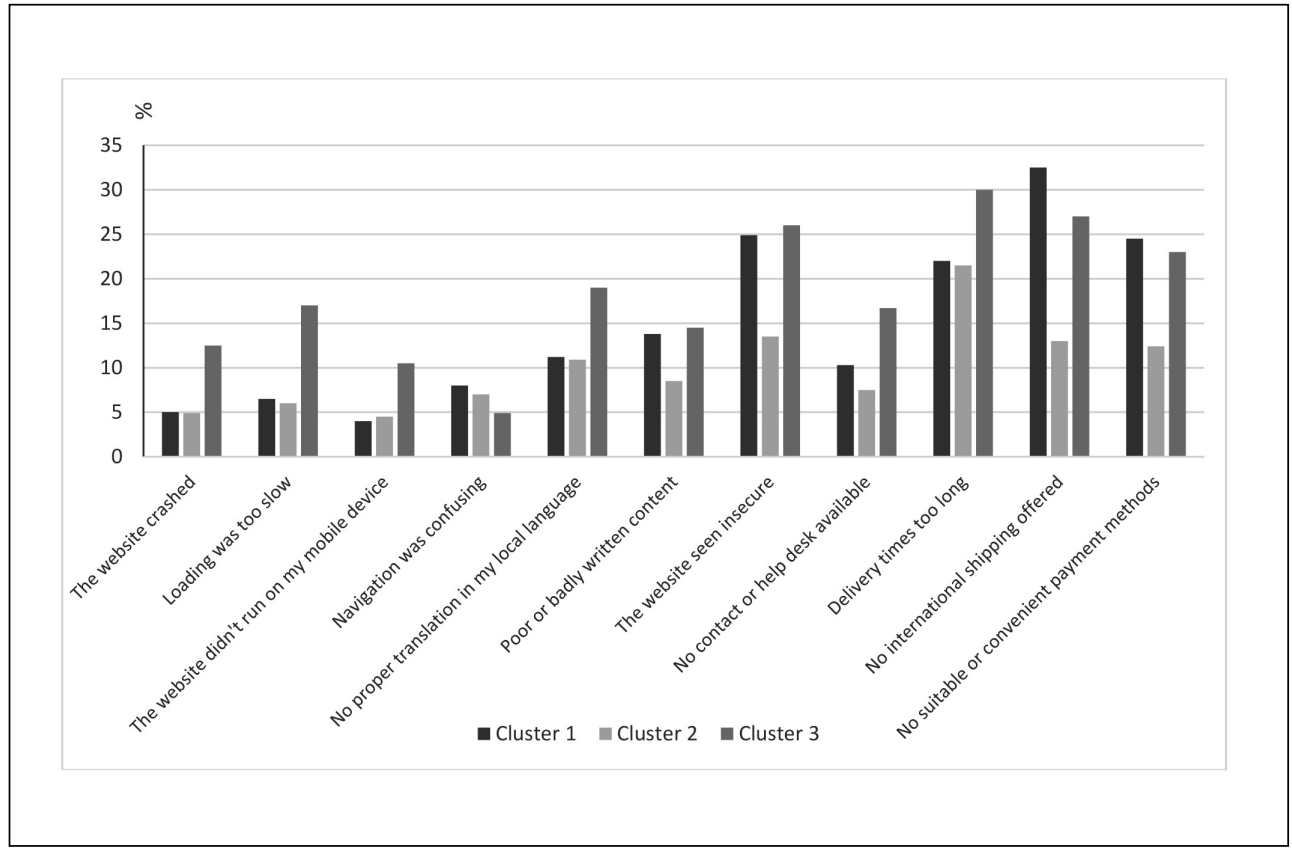

Source: own

other. This combination of characteristics will ensure the higher accuracy of user experience and website usability.

The results could be used by companies in the following way:

1. select the country for potential market penetration,

2. examine the degrees of membership in the particular clusters,

3. from description above, determine how much effort is necessary to prepare the website that is user-friendly according to users in particular country and compare it to capacities at company's disposal,

4. make a decision about launching/not launching the website in the selected country.

Limitations of the study:

- the data are collected on the country aggregate level. It would be better if we have individual-level data because we could find groups of different users more easily;

- the predictive accuracy of the model is debatable. The results need to be tested in the real world in order to prove/disprove its correctness;

- there is not a single solution in factor analysis and use of different rotation might also affect the results of clustering conducted afterwards.

\section{Conclusions}

Website usability affects the purchasing behavior and willingness of users to purchase a product online. The main objective of our study was to analyze the website usability issues users have when purchasing products from abroad. The topic of website usability was examined in our previous study and in the studies by Zaied et al. (2015), Pilar and García (2014), Liu, Li, and $\mathrm{Hu}$ (2013), and Green and Pearson (2011). By using factor analysis, we created two factors consisting of variables explaining website usability issues. Moreover, with the use of fuzzy clustering, we created and described three groups of users based on their perception of website usability issues during online purchasing from abroad. 
These results can be used by marketing, sales and IT professionals in companies operating on some or more of the observed markets in order to better prioritize their efforts towards potential customers. In addition, the results can be used in the educational process of educational institutions with economic- and business-oriented field of study. The results of our analysis pointed out to one particular group of Internet users (falling to Cluster 3 ) which are highly sensitive when it comes to the usability issues during their online purchasing process. It is recommended to pay a special attention to analyze and fine-tune user experience for the companies who offer their products online on the markets included in this cluster, especially when it comes to ensure security of the user, proper delivery and appropriate selection of payment methods. As countries included in Cluster 3 are not geographically close, we assume the difference in payment preferences. In order to overcome this issue, we suggest usage of tools like Adyen which provides payment methods based on the local payment standards and customs. Users from countries belonging to Cluster 1 and 2 are not as sensitive to usability issues as users in Cluster 3, however, users from Cluster 1 behave in the similar fashion as users in Cluster 3 when it comes security, shipping and payment methods. Thus, companies should prioritize the optimization of these three areas for the users from these countries. Users from countries included in Cluster 2 seem little bit indifferent in terms of usability issues - with the exception of delivery time. Companies serving customers in these countries should optimize the selection of shipping companies in order to provide their customers with goods as soon as possible.

In order to understand the issue more in detail, the future research should be focused on the following areas:

- Collect and analyze the data on more granular level in order to find patterns that couldn't be observed in the aggregated data on a country level. It will allow researchers to create more specific clusters of users based more on their characteristics than just geographic location.

- Examine more in detail why users in Cluster 3 are that sensitive in terms of usability issues and why users in Cluster 1 are indifferent in terms of their experience with the website during purchase online.
- Estimate the financial loss as a result of not convenient user experience for users during their online purchase.

- Determine the impact of particular usability issues on the abandonment of the purchasing process and estimate the financial loss of the individual website issues.

- Analyze the future trends in behavior of users purchasing goods from online stores and compare them with the development of online stores' user experience.

The knowledge of abovementioned issues would help prioritize the optimization efforts of the companies more in detail, and financial impact would persuade more companies to put more emphasis into the optimization of user experience.

\section{References}

Abu-Jamous, B., Fa, R., \& Nandi, K. A. (2015). Integrative Cluster Analysis in Bioinformatics. West Sussex: John Wiley \& Sons.

Aziz, N. S., Kamaludin, A., \& Sulaiman, N. (2013). Assessing Web Site Usability Measurement. International Journal of Research in Engineering and Technology, 2(9), 386-392. https://dx.doi. org/10.1080/15332860802086318.

Braddy, P. W., Meade, A. W., \& Kroustalis, C. M. (2008). Online recruiting: The effects of organizational familiarity, website usability, and website attractiveness on viewers' impressions of organizations. Computers in Human Behavior, 24(6), 2992-3001. https://dx.doi. org/10.1016/j.chb.2008.05.005.

Bucko, J., Ferencová, M., \& Kakalejčík, L. (2015). Analýza faktorov ovplyvňujúcich nakupovanie prostredníctvom internetu. MANEKO: manažment a ekonomika podniku $=$ journal of corporate management and economics, 7(2), 177-185.

Cappel, J. J., \& Huang, Z. (2015). The Iceberg Model of Website Usability. Issues in Information Systems, 16(1), 21-27.

Casaló, L. V., Flavián, C., \& Guinalíu, M. (2008). The role of satisfaction and website usability in developing customer loyalty and positive word-of-mouth in the e-banking services. International Journal of Bank Marketing, 26(6), 399-417. https://dx.doi. org/10.1108/02652320810902433. 
Consumer Barometer. (2015). Methodology. Retrieved April 18, 2016 from https://www.consumerbarometer.com/en/ about/\#methodology.

Dingli, A., \& Cassar, S. (2014). An Intelligent Framework for Website Usability. Advances in Human-Computer Interaction, 5, 1-13. https://dx.doi.org/10.1155/2014/479286.

Green, D. T., \& Pearson, J. M. (2011). Integrating website usability with the electronic commerce acceptance model. Behaviour \& Information Technology, 30(2), 181-199. https:// dx.doi.org/10.1080/01449291003793785.

Höppner, F., Klawonn, F., Kruse, R., \& Runkler, T. (1999). Fuzzy Cluster Analysis: Methods for Classification, Data Analysis and Image Recognition. West Sussex: John Wiley \& Sons.

Kakalejčík, L. (2016). Analysis of website elements as conversion drivers. Scientific Letters of Academic Society of Michal Baludansky, 4(2), 40-43.

Kauffmann, L., \& Rousseeuw, P. J. (2005). Finding Groups in Data: An Introduction to Cluster Analysis. Hoboken: Willey\&Sons.

Krishnapuram, R., Joshiet, A., \& Nasraoui, O. (2001). Low-complexity fuzzy relational clustering algorithms for web mining. IEEE Transactions on Fuzzy Systems, 9(4), 595-607. https://dx.doi.org/10.1109/91.940971.

Krug, S. (2014). Don't Make Me Think: A Common Sense Approach to Web and Mobile Usability. San Francisco: Pearson.

Law, E. L., \& Van Schaik, P. (2014). Attitudes towards user experience (UX) measurement. International Journal of HumanComputer Studies, 72(6), 526-541. https:// dx.doi.org/10.1016/j.ijhcs.2013.09.006.

Liu, Y., Li, H., \& Hu, F. (2013). Website attributes in urging online impulse purchase: An empirical investigation on consumer perceptions. Decision Support Systems, 55(3), 829-837. https://dx.doi.org/10.1016/j. dss.2013.04.001.

Lowry, P. B., Kim, H., Kim, J., Lee, Y., Chae, M., \& Choi., Y. (2006). A theoretical model and empirical results linking website interactivity and usability satisfaction. In System Sciences, 2006. HICSS'06. Proceedings of the 39th Annual Hawaii International Conference on System Sciences (pp. 123a-123a). https://dx.doi.org/10.1109/HICSS.2006.33.

Maechler, M., Rousseeuw, P., Struyf, A., Hubert, M., Hornik, K., Studer, M., \& Roudier,
P. (2014). Cluster analysis extended. Retrieved March 18, 2017 from http://wis.kuleuven. be/stat/robust/papers/2005/maechleretalrpackagecluster-cran-2005.pdf.

Meloun, M., Hill, M., \& Militký, J. (2012). Statistická analýza vícerozměrných dat $\checkmark$ príkladech. Praha: Academia.

Montero, F., González, P., Lozano, M., \& Vanderdonckt, J. (2005). Quality Models for Automated Evaluation of Web sites Usability and Accessibility. In Proceedings of the International COST294 Workshop on User Interface Quality Model (pp. 37-43). Rome: Interact.

Pallot, M., \& Pawar, K. (2012). A holistic model of user experience for living lab experiential design. In 18th International ICE Conference on Engineering, Technology and Innovation (ICE) (pp. 1-15). https://dx.doi. org/10.1109/ICE.2012.6297648.

Pilar, J. M. A., \& García, S. D. B. (2014). Website Design As Moderating Factor of Online User Behavior. In XXVI Congreso de Marketing (pp. 1-13). Available at http://hdl.handle. net/10481/34953.

Ries, E. (2011). The Lean Startup: How Today's Entrepreneurs Use Continuous Innovation to Create Radically Successful Businesses. New York: Crown Business.

Sivaji, A., \& Tzuan, S. S. (2012). Website User Experience (UX) Testing Tool Development using Open Source Software (OSS). In Network of Ergonomics Societies Conference (SEANES) (pp. 1-6). https://dx.doi. org/10.1109/seanes.2012.6299576.

Sohrabi, B., Mahmoudian, P., \& Raeesi, I. (2011). A framework for improving e-commerce websites usability using a hybrid genetic algorithm and neural network system. Neural Computing and Applications, 21(5), 1017-1029. https://dx.doi.org/10.1007/s00521-011-0674-7.

Stankovičová, I., \& Vojtková, M. (2007). Viacrozmerné štatistické metódy s aplikáciami. Bratislava: lura Edition.

Sutherland, J. (2014). Scrum: The Art of Doing Twice the Work in Half the Time. New York: Crown Business.

Timm, H., Borgelt, C., \& Kruse, R. (2004). An extension to possibilistic fuzzy cluster analysis. Fuzzy Sets and Systems, 147(1), 3-16. https://doi.org/10.1016/j.fss.2003.11.009. 


\section{Informační management}

Wu, J. (2016). Principal Component Analysis. Retrieved March 18, 2017 from http://cs.nju.edu.cn/_upload/tpl/00/ed/237/ template237/paper/PCA.pdf.

Zaied, A. N., Hassan, M., \& Mohamed, I. (2015). Applying Website Usability Testing Techniques to Promote E-services. ACSIJ Advances in Computer Science: an International Journal, 4(5), 54-60. doc. RNDr. Jozef Bucko, PhD. Technical University of Košice Faculty of Economics Department of Applied Mathematics and Business Informatics Slovakia jozef.bucko@tuke.sk

Mgr. Lukáš Kakalejčík Technical University of Košice Faculty of Economics Department of Applied Mathematics and Business Informatics Slovakia lukas.kakalejcik@tuke.sk 


\title{
Abstract
}

\section{WEBSITE USABILITY AND USER EXPERIENCE DURING SHOPPING ONLINE FROM ABROAD}

\author{
Jozef Bucko, Lukáš Kakalejčík
}

The Internet became a non-stop market of goods and services. As the market is oversaturated, companies are forced to fight for each customer because it is easier than ever to change the partner who will fulfil customer's needs. User experience and website usability is an important factor during the online purchasing process. The main objective of our study was to analyse the website usability issues users have when purchasing products from abroad. In order to achieve our objective, we analysed the data from Consumer Barometer. We conducted the principal components analysis, followed by fuzzy clustering in order to determine the groups of users based on the perceived website usability problems during online purchasing. By using factor analysis, we created two factors consisting of variables explaining website usability issues. Moreover, with the use of fuzzy clustering, we created and described three groups of users based on their perception of website usability issues during online purchasing from abroad and assigned countries of origin of these users. The results of our analysis pointed out to one particular group of Internet users (Cluster 3) which are highly sensitive when it comes to the usability issues during their online purchasing process. These results can be used by companies operating on one or more of the observed markets in order to improve their performance when serving their potential customers. In addition, the results can be used in the educational process of educational institutions which field of study is focused on economics and business. As we did not find any similar study, this study extends the current knowledge of the issue and gives insight to the contemporary needs of international online shoppers.

Key Words: Website usability, user experience, online shopping, cluster analysis, consumer barometer.

JEL Classification: M31, M15, C38.

DOI: 10.15240/tul/001/2018-3-013 